\title{
CORPORATE DIPLOMACY GO-JEK MELALUI PENDIRIAN GO-VIET 2018-2020: TINJAUAN NATION BRANDING INDONESIA DI VIETNAM
}

\author{
Hino Samuel Jose*); Pradipta Anugra Firdausa; \\ Muhammad Khalifah; Novia Ayuningsih \\ Fakultas Ilmu Sosial dan Ilmu Politik, Universitas Pembangunan Nasional Veteran Jakarta \\ *)email:abrahamhinosamueljose@upnvj.ac.id
}

Paper Accepted: 30 Juni 2021

Paper Reviewed: 01-07 Juli 2021

Paper Edited: 08-15 Juli 2021

Paper Approved: 18 Juli 2021

\begin{abstract}
ABSTRAK
Berdirinya GO-JEK sebagai salah satu perusahaan unicorn tentu sangat menguntungkan politik ekonomi Indonesia melalui diplomasi publik yang dilakukan oleh GO-JEK melalui pendirian GO-VIET pada tahun 2018. Melalui teori dan konsep dari corporate diplomacy, telah terlihat perubahan paradigma dalam hubungan diplomasi. Dalam konteks politik ekonomi, terutama diplomasi publik, citra dari negara asal terobjektifikasikan dari bagaimana aktor non-negara yang berinteraksi dengan masyarakat asing tersebut berproses. Artikel ini menjelaskan implementasi dari corporate diplomacy untuk memajukan perusahaan asal Indonesia dalam layanan jasa di Asia Tenggara hingga global. Adapun potensi yang tersurat dalam interdependensi Indonesia-Vietnam melalui GO-VIET dalam jangka panjang dapat menyaingi pemain pasar sebelumnya dalam sektor transportasi online. Dari hal ini, maka politik ekonomi Indonesia melalui diplomasi korporat ini telah memiliki nafas baru untuk pencapaian visi pengembangan ekonomi Indonesia maju di tahun mendatang.
\end{abstract}

Kata Kunci : diplomasi korporat, GO-JEK, Indonesia, Vietnam, citra negara

\section{PENDAHULUAN}

Politik luar negeri baik dalam level bilateral, regional, maupun multilateral tidak hanya berbicara pada konteks tradisional dimana interaksi kerjasama dan norma-norma yang dibahas hanya dapat dilakukan oleh para aktor negara saja. Kenyataanya, perkembangan teknologi membuat batas-batas negara ditembus dan digitalisasi menjadi suatu kebiasaan yang menunjukan kemajuan peradaban manusia. Perkembangan teknologi sebagai akibat dari globalisasi nyatanya telah membawa kemajuan yang pesat di berbagai sektor, salah satunya adalah di bidang transportasi. Perkembangan teknologi ternyata mampu menciptakan transformasi tren transportasi dimana Ojek berubah menjadi Ojek Online (ojol) yang dapat dipesan dengan mudah hanya dengan mendownload aplikasi dari penyedia jasa layanan transportasi Online. Di Indonesia, salah satu perusahaan yang bergerak dalam penyediaan jasa layanan moda transportasi Online adalah GO-JEK. Perusahaan yang didirikan di tahun 2010 oleh Menteri Pendidikan Republik Indonesia Nadiem Makarim awalnya hanya menyediakan layanan transportasi berupa antar jemput penumpang, namun seiring perkembangan GO-JEK juga mulai menyediakan berbagai layanan seperti pengiriman barang, pembelian makanan, pembayaran, dan belanja keperluan bulanan (GOJEK, n.d).

Berdasarkan riset Lembaga Demografi Fakultas Ekonomi dan Bisnis Universitas Indonesia (LD FEB UI) di tahun 2019, GO-JEK dan mitranya setidaknya telah memberikan kontribusi dengan menyumbang Rp 104,6 Triliun terhadap perekonomian Indonesia (Kumparan, 2020). Bahkan, menurut Wakil Kepala LD FEB UI Dr. Paksi C. K. Walandouw apabila diproyeksikan dengan perhitungan metode Gross Domestic Product (GDP) maka ekosistem digital dari GOJEK setidaknya setara dengan 1\% GDP nasional Indonesia. Melalui inovasi-inovasi tersebut 
dukungan terhadap GO-JEK yang notabenenya merupakan produk anak bangsa setidaknya per2019 GO-JEK telah diunduh sebanyak 155 juta pengguna dengan pengguna aktif di Kawasan Asia Tenggara mencapai 36,3 juta jiwa (Andriani, 2019; Moore, 2020). Dengan semakin berkembangnya GO-JEK tentunya tidak mengejutkan bahwa perusahaan ini berhasil menarik minat investor asing dunia seperti, Google, Temasek, Warburg Pincus, dan Tencent untuk menyuntikan dana ke perusahaan tersebut (Franedya, 2019). Pada tahun 2018 menyusul Tencent Google menyuntikan dana mencapai Rp 16 Triliun untuk GO-JEK (Savithri, 2018) dengan nominal investasi tersebut tentunya akan semakin memudahkan GO-JEK untuk lebih leluasa mengembangkan perusahaannya terutama melakukan ekspansi. Ekspansi ini adalah langkah ambisius yang secara optimis digagas oleh Nadiem Makarim yang merupakan pendiri GO-JEK sebelum masuk ke pemerintahan.

Semakin berkembangnya GO-JEK mengantarkan perusahaan ini menjadi salah satu dari 3 perusahaan Indonesia yang mencapai tingkatan Unicorn yaitu GO-JEK, Tokopedia, dan . Unicorn merupakan gelar yang didapatkan suatu perusahaan startup ketika memiliki nilai valuasi lebih dari US\$ 1 miliar (Ramadhani, 2019). Bahkan menurut riset startup CB Insights dalam laporannya berjudul "The Global Unicorn Club", GO-JEK telah memiliki nilai valuasi mencapai US\$ 10 miliar sehingga layak mendapatkan gelar Decacorn (Zaenudin, 2019). Melalui valuasi yang telah melebihi US\$ 10 Miliar yang tentunya berpotensi untuk lebih naik nilainya di tahun yang akan datang, membuat pihak manajemen GO-JEK pastinya mempertimbangkan untuk melakukan ekspansi besar-besaran ke beberapa negara lainnya terutama Kawasan Asia Tenggara untuk meluaskan pasar.

Niat ekspansi GO-JEK ke berbagai negara terutama di Kawasan Asia Tenggara sepertinya diaminkan oleh Nadiem Makarim di tahun 2018 yang ketika itu masih menjadi CEO dari GO-JEK. Ekspansi besar-besaran yang dilakukan oleh GOJEK di beberapa negara akhirnya melahirkan saudara, salah satunya adalah GO-VIET yang beroperasi di Vietnam. Bahkan Presiden Indonesia Joko Widodo atau Jokowi dan beberapa pejabat Indonesia pun hadir dalam peresmian GO-VIET di Hanoi, Vietnam. Presiden Jokowi juga menegaskan bahwa dengan adanya ekspansi GO-JEK menandakan bahwa teknologi Indonesia sudah mulai diadopsi dan diterima oleh negara lain, dia juga menegaskan bahwa akan mendukung teknologi Indonesia yang masuk ke negara lain (DW, 2018). Dengan adanya GO-VIET merupakan salah satu dari rencana pemerintah Indonesia untuk meningkatkan hubungan dagang bilateral dengan Vietnam setidaknya Jokowi juga menargetkan perdagangan antar kedua negara mencapai US\$ 10 miliar di tahun 2020 (DW, 2018).

Dari fenomena keberhasilan GO-JEK sebagai perusahaan menandakan pula bagaimana peran korporat dalam meningkatkan citra negara. Tren diplomasi sejatinya mulai mengalami pergeseran terutama di era kontemporer pasca Perang Dingin, dimana sebelumnya diplomasi masih sangat kental dengan peran negara sebagai aktor utama dalam mewujudkan kepentingan nasional. Perubahan tren diplomasi tradisional menuju kearah yang lebih modern tidak semerta-merta terjadi begitu saja namun, disebabkan oleh peran globalisasi yang begitu massif sehingga menimbulkan perkembangan teknologi informasi dan komunikasi di berbagai belahan penjuru dunia menggantikan status quo yang telah bertahan begitu lama. Diplomasi tidak lagi selalu mengedepankan model hard diplomasi yang begitu keras dan militeristik. Namun, beralih ke bentuk yang lebih terselubung dan menargetkan masyarakat internasional. Salah satu bentuk soft diplomasi yang ada di era kontemporer saat ini adalah public diplomacy dimana aktor yang berperan tidak lagi hanya aktor negara melainkan, juga aktor non-negara seperti Multi dan Transnational Cooperation, NGO, serta masyarakat seperti diaspora.

Hal yang menarik dalam artikel ini adalah akan terdapat kajian mengenai bagaimana peran GO-JEK sebagai aktor diplomasi publik Indonesia di Vietnam melalui GO-VIET. Peran pelaku usaha merupakan faktor kunci dalam mempercepat keberhasilan integrasi suatu daerah, terutama di negara-negara berkembang. Sebagai negara dengan wilayah dan jumlah penduduk terbesar di Asia Tenggara, Indonesia menjadi daya tarik yang kuat bagi negara-negara di sekitarnya. Dalam kerangka Integrasi Pasar Komunitas ASEAN, daya serap pasar Indonesia yang tinggi akan sangat menjanjikan. Namun Integrasi Pasar ini juga harus membawa keuntungan bagi Indonesia yang berpeluang menembus pasar seluruh negara di Kawasan Asia Tenggara. Oleh karena itu di dalam kesinambungan yang kompetitif antarnegara, dan situasi persaingan yang semakin ketat, Indonesia baik di tingkat nasional maupun daerah harus dapat terus meningkatkan kemampuan dan kreativitasnya guna memaksimalkan potensi ini.

Pendiri dari GO-JEK, Nadiem Makarim menuturkan bahwa tujuan GO-JEK berkolaborasi dengan Vietnam dan pemerintahannya adalah supaya manfaat teknologi GO-JEK bisa memberikan dampak luas bagi semua kalangan, baik bagi konsumen yang menginginkan pelayanan yang cepat dan kompetitif, maupun mitra pengemudi yang mencari penghasilan tambahan. Itu merupakan dampak langsung yang dapat dirasakan oleh masyarakat lokal di wilayah 
operasional yang menggunakan layanan tersebut. Namun yang dibahas saat ini akan berupa pertanyaan bagaimana dengan dampak dari aktivitas bisnis GO-JEK sebagai penyedia layanan on-demand berbasis aplikasi digital itu sendiri terhadap perkembangan ekonomi Indonesia.

Mengetahui bahwa GO-JEK merupakan unicorn asal Indonesia yang mulai menunjukkan eksistensi nya di panggung perekonomian dunia, menjadi urgensi dari penelitian ini bahwa kita perlu menganalisa sejauh mana kontribusi dari ekspansi GO-JEK ke negara Vietnam terhadap perusahaan itu sendiri dan terhadap Indonesia, nation branding Indonesia kepada vietnam ditinjau dari corporate diplomacy GO-JEK sehingga apabila berkiblat dengan salah satu misi GO-JEK yaitu untuk membangun komitmen jangka panjang sebagai layanan yang dimanfaatkan di banyak negara terutama ASEAN menjadi lebih tepat target dan membawa lebih banyak dampak positif bagi kemajuan perekonomian Indonesia serta nation branding dalam skala kawasan dan secara berkesinambungan menuju level global secara luas dan menyeluruh. Pemerintah Indonesia sendiri antusias untuk rencana ini dan memfasilitasi GOJEK yang terbukti ketika Presiden Joko Widodo memberi restu kepada GO-VIET dalam agenda kunjungannya di World Economic Forum 2018 di Vietnam.

Penelitian ini akan menjelaskan bagaimana operasionalisasi dari konteks diplomasi korporat sebagai salah satu upaya politik ekonomi Indonesia. Upaya Indonesia disini perlu diketahui adalah untuk mengembangkan korporasi Indonesia untuk melebarkan sayapnya di pasar ASEAN. Diplomasi publik dalam hal ini menjadi konsep utama yang menjadi salah satu lingkup utama yang mengatasi diplomasi korporat untuk nation branding Indonesia. Adapun artikel ini juga membahas mengenai dinamika GO-VIET semenjak berdiri.

\section{Kerangka Teori}

\section{Konseptualisasi Politik Ekonomi Melaui Pendekatan Diplomasi Publik}

Dalam pendekatan politik, diplomasi publik yang membawa konten nation branding menekankan konseptualisasi yang sama yaitu memiliki pendekatan yang sama namun hanya berbeda dalam hal persepsi (Gilboa, 2008; Szondi, 2008) - maupun pendekatan yang memandang bahwa pendekatan politik dalam konteks diplomasi publik adalah sama secara total (Anholt, 2007). Walaupun persepsi akademiknya berbeda dikarenakan kedua hal narasi diatas merupakan manifestasi dari mazhab Amerika dan mazhab Eropa, kedua hal tersebut sama-sama menjelaskan bagaimana pendekatan politik di era kontemporer seperti apa yang terjadi pada dekade ini lebih menekankan bagaimana branding dan identitas politik suatu negara dapat dikomunikasikan dan dilaksanakan secara kolektif oleh semua aktor baik negara maupun non-negara. Tentunya ini menunjukan bahwa paradigma politik tidak hanya dari dimensi ekonomi, namun secara keseluruhan sudah bergeser dari geopolitik menuju lanskap branding dan pencitraan negara (Van Ham, 2001).

Adapun untuk konsepsi diplomasi publik ini sendiri juga dilakukan untuk menaruh merek/ identitas nasional Indonesia di luar negeri. Hal ini sejalan dengan apa yang diargumentasikan oleh Wang (2006) dan bahwa diplomasi publik menentang monopoli peran pemerintah dan cocok untuk berbagai isu sektoral seperti ekonomi, budaya, politik, dan sebagainya dalam mendukung strategi bisnis (Wang, 2006). Usaha soft power ini tentu mencakup diplomasi komersial yang digunakan untuk menyelesaikan tantangan dalam kebijakan diplomasi ekonomi Indonesia tetapi juga untuk mendorong pembangunan domestik. Narasi ini sesuai dengan apa yang dikemukakan oleh Potter (2006) bahwa diplomasi publik mendorong bagaimana tercipta keberpihakan asing dalam agenda nasional untuk dampak secara publik maupun secara khusus untuk kepentingan politik negara (Potter, 2006).

\section{Diplomasi Kontemporer dalam Politik Internasional}

Identitas Indonesia dalam studi kasus yang ditinjau di penelitian ini mengutamakan bagaimana pemerintah mampu untuk mendorong aktor swasta seperti GO-JEK yang merupakan perusahaan orisinil Indonesia melakukan ekspansi dan membawa identitas Indonesia melalui kerjasama internasional perusahaan GO-JEK di Vietnam. Berdasarkan narasi tersebut, maka paradigma dalam menjelaskan studi kasus ini adalah gagasan politik ekonomi melalui corporate diplomacy ini dapat dipahami sebagai suatu langkah yang akan menekankan bagaimana nation branding dan citra suatu perusahaan yang berasal dari suatu negara lain memperoleh pasar mereka di negara lain. Pada penelitian ini, GO-JEK tentu menjadi aktor diplomat komersil yang mendukung tujuan pemerintahan Indonesia dalam mengembangkan pasar ekonomi digital dan layanan transportasi hingga ke ASEAN. Visi ini menunjukan bahwa diplomasi kontemporer membutuhkan peran aktor komersil dalam mendorong visi negara sebagai aktor rasional yang berusaha menciptakan interdependensi.

Dalam studi politik internasional, hubungan luar negeri biasanya dijalankan oleh aktor pemerintahan yang dimana diklasifikasikan lebih dalam pada konvensi Wina mengenai hubungan 
diplomatik (Vienna Convention on Diplomatic Relations), adapun diplomasi yang dilakukan oleh aktor non-pemerintah secara langsung dikenal sebagai diplomasi publik. Diplomasi kontemporer konseptualisasinya mengarah kepada diplomasi yang melibatkan aktor sipil dengan mengarusutamakan nilai pelibatan dan pengaruh kepada masyarakat di luar negeri dalam pelaksanaan politik luar negerinya (Jose, 2021). Secara tekstual, diplomasi publik menurut Cull (2008) dalam karyanya mengenai diplomasi publik menjelaskan beberapa cara untuk melaksanakan diplomasi publik seperti melalui observasi media, advokasi dari pertukaran budaya, usaha diplomasi yang melibatkan masyarakat sipil, dan penggunaan media massa yang tepat untuk mempengaruhi masyarakat di negara lain sesuai dengan objektif politik luar negeri. Penekanan pada aspek media massa, keterlibatan aktor non-negara, dan observasi media adalah kunci penting dalam implementasinya (Cull, 2008).

\section{Corporate Diplomacy (Diplomasi Korporat) dalam Politik Ekonomi Internasional}

Dengan gagasan diplomasi publik sebagai suatu teori dasar dalam menjelaskan politik ekonomi Indonesia di luar negeri, dapat dimengerti bahwa trek politik luar negeri tidak hanya dapat dilakukan oleh pemerintah melainkan oleh aktor swasta seperti korporasi (perusahaan). Peran korporasi disini juga menawarkan suatu alternatif terhadap tindakan serta peran yang dilakukan oleh pemerintah dalam politik luar negeri yang nyatanya bersifat disfungsional, proteksionis, inkonsisten, dan tidak populer (Drezner, 2017). Sehingga nyatanya, peran korporasi disini tidak hanya sebagai aktor yang melakukan remedial terhadap kekurangan pemerintah, namun juga memiliki keterkaitan untuk mempengaruhi arah politik luar negeri, terutama dalam bidang perekonomian. Salah satu contohnya adalah ketika Inggris menyatakan keluar dari Uni Eropa, perusahaan-perusahaan asal Inggris seperti Bank dan perusahaan dagang lain mempersiapkan rencana dan strategi untuk menjaga akses mereka ke pasar di negara-negara Uni Eropa untuk ketahanan perusahaan mereka (Bolewski, 2018). Dari contoh tersebut, korporasi dituntut untuk proaktif dan independen dalam kontribusinya terhadap perubahan norma dalam bisnis (Scherer et al, 2006). Namun batas-batas resmi antar negara masih ada, sehingga dalam hal ini pemerintah sebagai aktor utama dalam melaksanakan hubungan internasional dan jalur diplomasi resmi harus membagi tupoksi antara korporasi dan pemerintah sebagai bentuk perluasan pengaruh ekonomi eksternal dalam diplomasi ekonomi: pemerintah sebagai pembuat kebijakan dan menetapkan norma, basis hukum, dan arahan kerjasama; dan korporasi sebagai pelaksana bisnis transnasional mereka serta memperhatikan CSR (corporate social responsibility) dan neraca untung rugi mereka terhadap kondisi masyarakat dan performa bisnis di negara tempat mereka beroperasi.

Dengan sifat korporasi sebagai aktor yang termotivasi oleh keuntungan dan peluang (profitoriented), maka mereka akan cenderung untuk mencari ataupun menciptakan kondisi yang 'nyaman' serta 'memuaskan' bagi operasi bisnis mereka, sehingga kondisi sosial politik di suatu negara akan sangat mempengaruhi aktivitas mereka (Henisz, 2014). Sehingga, pemerintah memiliki mandat yang secara intangible terbentuk untuk kembali melakukan monitoring dan memfasilitasi perusahaan mereka yang beroperasi di negara lain baik melalui sanksi ekonomi/ perjanjian ekonomi komprehensif (CEPA)/ free trade agreement (FTA)/ perjanjian bilateral yang memuat norma dan ketentuan spesifik untuk membantu perusahaan mereka sesuai dengan kepentingan diplomasi ekonomi negara tersebut.

Adapun contoh yang dapat dilihat adalah studi kasus yang ditinjau di artikel ini maupun contohnya ketika perusahaan kelapa sawit Indonesia tidak bisa melakukan ekspor dikarenakan kebijakan lingkungan Uni Eropa, maka pemerintah Indonesia melakukan protes dan melaksanakan dispute settlement sesuai mekanisme WTO yang dikenal sebagai kasus DS-592 (Indo Premier, 2021). Hal ini cukup menjelaskan bagaimana globalisasi yang merupakan dua mata pedang harus dimitigasi dan diantisipasi oleh para aktor dalam menjaga kesinambungan peluang dan keuntungan yang menjadi motif ekonomi mendasar baik secara politik maupun bisnis (Henisz, 2016). Hal ini sesuai dengan prinsip politik luar negeri yang dijunjung Indonesia yaitu salah satunya adalah mengikuti dan menghormati hukum internasional dan tatanan global yang telah terbentuk untuk mendorong norma perdamaian dan kesejahteraan.

\section{METODE PENELITIAN}

Dalam penulisan penelitian ini, penulis menggunakan jenis penelitian deskriptif analitis yang menggambarkan dan juga menjelaskan langkah-langkah, serta peluang dan tantangan Indonesia dalam melakukan nation branding di Vietnam melalui GO-VIET pada periode tahun 2018-2020. Pendekatan yang digunakan penulis adalah pendekatan kualitatif dengan menggunakan metode content analysis, yaitu dengan menganalisis, menyebutkan, serta menjelaskan berbagai sumber yang telah diperoleh untuk dikaitkan dengan permasalahan atau fenomena yang diteliti. Teori dan konseptualisasi yang digunakan mendukung elaborasi untuk menjelaskan bagaimana politik ekonomi kontemporer melalui 
corporate diplomacy dijelaskan untuk memahami bagaimana GO-VIET berkembang di Vietnam serta keberhasilan Indonesia dalam mendorong pendekatan baru ini untuk menjadi powerhouse ASEAN

Menurut Saryono (2010), penelitian kualitatif merupakan penelitian yang digunakan untuk menemukan, menggambarkan, menyelidiki, serta menjelaskan kualitas atau keistimewaan dari pengaruh atau faktor sosial yang tidak dapat digambarkan, dijelaskan, ataupun diukur melalui pendekatan kuantitatif. Dalam penelitian ini penulis juga menggunakan teknik pengumpulan data studi kepustakaan, dimana penulis mengumpulkan berbagai data dari berita, buku, web resmi, jurnal, laporan resmi, artikel, skripsi, dan sumber internet. Dari berbagai sumber diatas, diharapkan dapat membantu penulis melakukan penelitian mengenai langkah-langkah, serta peluang dan tantangan Indonesia dalam melakukan nation branding di Vietnam melalui GO-VIET pada periode tahun 2018-2020.

\section{HASIL DAN PEMBAHASAN}

\section{Diplomasi Korporat dan Pengaruh Ekonomi Indonesia Melalui GO-VIET}

Indonesia berbangga akan kehadiran GO-JEK sebagai salah satu unicorn buatan anak bangsa yang dimana dengan hadirnya GO-JEK serta meroketnya performa bisnis GO-JEK di Indonesia membuat Indonesia memiliki merek lokal untuk layanan transportasi online multi-servis yang mampu menyaingi merek transportasi online asal luar negeri seperti Grab dan Uber. GO-JEK sendiri membawa ciri khas transportasi publik informal Indonesia, yaitu Ojek motor yang dimana label ini sudah berubah menjadi salah satu transportasi resmi yang terjangkau bagi seluruh kelas masyarakat. Branding semacam inilah yang membuat GO-JEK sebelum ekspansi ke negara lain mampu untuk meningkatkan valuasi pasar dan jumlah sumber daya yang mereka miliki. Citra perusahaan GO-JEK inilah yang menurut (Szondi, 2008) dinyatakan sebagai suatu aplikasi dari citra branding dan marketing yang digunakan untuk mempromosikan suatu citra dan menjadi bagian dari kehidupan sehari-hari masyarakat bahkan lebih dari strategi pemerintah. Hal ini menjadi salah satu konten dari diskursus diplomasi publik itu sendiri dan di objektifikasikan sebagai suatu langkah pendekatan soft power untuk mempengaruhi masyarakat dan pemerintahan negara lain. Dalam kasus GO-JEK tentu kita melihat Indonesia berusaha untuk membawa interdependensi dengan Vietnam ke level yang lebih jauh dan sadar akan potensi pasar moda transportasi online di Vietnam yang dimana kondisi masyarakat dan struktur sosialnya sejenis dengan Indonesia. Oleh karena itu, GO-JEK melalui perusahaan brand Vietnamnya GO-VIET mampu untuk menjadi kompetitor di Vietnam melawan perusahaan transportasi terbesar di ASEAN seperti Grab.

Kepercayaan menjadi salah satu unsur penting baik dalam konteks diplomasi politik maupun interaksi para aktor secara umum. Dan dalam konteks nation branding, maka kepercayaan menjadi salah satu parameter penting dalam pencapaian kesepakatan dan langkah strategis dalam komunikasi untuk mengambil kesempatan yang baik (Fombrun, 1996). Dan intervensi yang dilakukan baik dalam proses komunikasi maupun dalam konteks politik harus didukung dengan peran media yang baik menurut Cull (2008) dan Deephouse (2000) merupakan cara komunikasi strategis yang dapat mendemonstrasikan citra yang memuat kepentingan yang ditujukan kepada masyarakat luas. Dengan citra yang baik, maka investor akan tertarik untuk menanamkan modal yang dapat memperbesar modal kapital GO-VIET di Vietnam sebagai layanan transportasi online yang mampu diandalkan. Tentu ini direfleksikan dari apa yang telah dilakukan GO-JEK di Indonesia ketika mereka mampu meraih kepercayaan investor yang dimana pada tahun 2016 GO-JEK menjadi unicorn dan menerima suntikan dana investor sebesar 50 Juta dollar AS (Pratama, 2016).

Penelitian yang ditulis oleh Prananda et al (2019) mengenai ekspansi GO-JEK sebagai pasar Indonesia di Asia Tenggara menyimpulkan dimana model strategi bisnis GO-JEK berpaku pada bagaimana penetrasi pasar dapat dijangkau dengan melihat kesempatan pengembangan baru yang mampu meningkatkan penjualan layanan melalui evaluasi terhadap kombinasi spektrum pasar-pasar tersebut. Dan GO-JEK dalam hal ini mampu untuk mempertahankan citra utamanya sebagai penyedia layanan jasa transportasi online tanpa harus mengalami kesulitan dalam melakukan diversifikasi layanan-layanan untuk kebutuhan masyarakat yang berubah (Prananda et al, 2020). Model bisnis seperti inilah yang mampu untuk mendukung kemulusan corporate diplomacy GOJEK melalui GO-VIET di Vietnam yang difasilitasi oleh pemerintahan Indonesia.

Adapun secara tekstual, model bisnis ini tertuang dalam model bisnis Ansoff Matrix Strategy yang mengutamakan 4 unsur yaitu strategi penetrasi pasar, strategi pengembangan pasar, strategi pengembangan produk, dan strategi diversifikasi yang ditinjau terhadap produk yang sudah ada sebelumnya dan inovasi baru yang akan dilakukan (Verhoeven \& Johnson, 2017). Dikarenakan perusahaan seperti GO-VIET adalah perusahaan yang bervaluasi besar, walaupun secara tekstual kritik seperti Schiller (1989) yang menyebut bahwa 
nation branding melalui diplomasi publik adalah semacam cultural imperialism. Maka, disimpulkan bahwa korporat dalam hal ini seperti GO-JEK merupakan salah satu senjata efektif untuk Indonesia dan pengaruhnya dapat dirasakan oleh masyarakat secara langsung dalam manifestasi politik ekonomi Indonesia di Vietnam.

\section{Nation Branding Indonesia Melalui GO-VIET}

Dalam diskursus ini, citra yang dibangun oleh negara dipercaya dapat mendorong proses diplomasi yang bertahan lama di tengah kompetisi para pelaku aktor ekonomi seperti korporat (Olins, 1999). Dengan motivasi agar citra dipandang positif oleh penduduk negara asing, umumnya usaha yang dilakukan akan melibatkan sektor ekonomi lebih banyak ketimbang politik dan beberapa ilmuwan juga meyakini bahwa konsep ini cukup erat kaitannya pula dengan teknik pemasaran.

Beberapa hal yang diupayakan oleh GO-JEK yang merupakan Unicorn asal Indonesia, dalam program ekspansinya ke beberapa negara di ASEAN secara tidak langsung berusaha menaikkan citra Indonesia melalui kemampuan teknologi dan pasar. Hal ini terlihat dimana GO-JEK sebelum peluncuran GO-VIET di Vietnam mengundang para pimpinan GO-VIET terlebih dahulu untuk melihat pasar Indonesia (Araya, 2018), dari situ beberapa citra yang dapat terlihat adalah bagaimana ojek menjadi transportasi publik informal di Indonesia. Melihat bagaimana perkembangan pasar di Indonesia dan mengkomparasikan dengan Vietnam yang ternyata notabenenya juga memiliki jumlah pengemudi kendaraan roda dua yang masif akhirnya GO-Viet juga berani menerapkan layanan ojek yang sama di Indonesia.

Aplikasi GO-VIET yang tentunya mengadopsi teknologi dari GO-JEK yang notabenenya berasal dari Indonesia juga merupakan salah satu upaya untuk mengenalkan performa teknologi yang dimiliki oleh Indonesia sehingga kedepan bukan tidak mungkin akan lebih banyak teknologi asal Indonesia meskipun tidak disponsori oleh pemerintah bisa masuk ke ranah Internasional. Meskipun saat ini layanan yang terdapat dalam GOVIET masihlah terbatas yakni, hanya GO-RIDE dan GO-SEND, namun kedepannya akan ada penambahan jumlah fitur. Dukungan terhadap teknologi dan ekspansi GO-JEK pun turut diapresiasi oleh pejabat Indonesia, mulai dari kalangan Menteri hingga Presiden Indonesia turut hadir dalam peresmian GO-VIET di Vietnam. Presiden Jokowi pun sangat mendukung ekspansi GO-JEK ke berbagai negara dan harapannya akan meningkatkan hubungan dagang dengan Vietnam.

Meskipun GO-VIET telah dihapus dan namanya telah diganti dengan GO-JEK dengan tujuan untuk memperkuat merek dagang (Isna,
2020), hal tersebut justru semakin meningkatkan identitas Indonesia di dalamnya. Merek dagang GO-JEK akan membawa Indonesia di dalamnya mengingat perusahaan ini adalah Unicorn asal Indonesia. Dengan adanya penguatan citra Indonesia melalui hal-hal tersebut maka dapat dipastikan akan ada potensi peningkatan kerjasama yang antara Indonesia dan Vietnam. Perusahaanperusahaan Indonesia akan semakin dilirik dan tentunya bukan tidak mungkin bahwa dalam beberapa tahun ke depan akan ada lebih banyak perusahaan yang melakukan ekspansi di Asia Tenggara.

\section{Dinamika Perkembangan GO-VIET dan Dampaknya Bagi Indonesia (2018-2020)}

GO-JEK memulai layanannya di Vietnam pada September 2018, dengan brand GO-VIET. Pada pertama kali peluncurannya, GO-VIET baru menyediakan dua fitur, yaitu Go-ride untuk layanan jasa transportasi, dan Go-send untuk layanan logistik pengiriman barang. Saat diwawancarai oleh CNN Indonesia dalam acara peluncuran GO-VIET di Hanoi, Vietnam pada September 2018, Nadiem Makarim selaku pendiri dan ketika itu masih menjadi CEO dari GO-JEK mengungkapkan bahwa jika dilihat dari sisi stakeholder dan pemerintahan, Vietnam sangat mendukung inovasi dan kompetisi dari berbagai macam layanan jasa ini, sehingga untuk regulasi menuju peluncuran GO-VIET ini pun didukung secara penuh dan dilancarkan dalam berbagai aspeknya. Berdasarkan penuturan Cheng Tuyen di Techbike.vn, GO-VIET diluncurkan, antusiasme masyarakat di Vietnam sangat besar. Saat kali pertama dibuka, antrian pendaftar untuk menjadi mitra pengemudi GO-VIET mencapai 100 meter, bahkan beberapa dari mereka harus datang kembali keesokan harinya karena kapasitas kantor yang tidak memadai. Promo kepada pengemudi yang ditawarkan pun tidak sedikit. Selain memberi diskon pada tiga bulan pertama, pengemudi alias mitra GO-VIET diberikan seragam gratis termasuk 2 helm, 2 kaos lengan panjang, seragam jaket, dan jas hujan. Mengenai tarifnya, GO-VIET memberi 30.000 Dong atau setara Rp18.000 untuk 6 kilometer pertama.

Bagi penumpang, GO-VIET mematok tarif 5000 Dong atau setara 3000 Rupiah untuk 6 kilometer pertama. Oleh karena kebijakan tersebut, sangat wajar bila di awal beroperasi, GO-VIET mengklaim bisa menggaet 35 persen pasar di Ho Chi Minh. Namun Grab sebagai kompetitor pun tak mau kalah, Grab semakin banyak menawarkan potongan harga dan menggunakan strategi "membakar uang" untuk menyusul GO-VIET untuk memenangkan pasar dan persaingan yang ketat.

Untuk implementasi dan penetapan kebijakan dalam skala lokal, GO-JEK memberikan 
keleluasaan kepada mitra lokal untuk memetakan tren pasar dan langkah bisnis di masing-masing negara. Hal ini terlihat dari kebijakan pemberian branding yang berbeda pada tahap awal ekspansinya di Vietnam yang dibawa dengan brand "GO-VIET". Pemberian nama yang menyesuaikan dengan negara Vietnam ini merupakan bagian dari pendekatan hiper-lokal, yang dilakukan agar layanan tersebut memiliki kedekatan dengan konsumen di negara Vietnam. Hal tersebut berlangsung selama dua tahun hingga target pasarnya cukup besar dan lebih dikenal oleh konsumen di negaranya masing-masing.

GO-JEK telah menarik 1 juta penumpang di Vietnam dalam waktu kurang dari 3 bulan. Setelah menyediakan layanan transportasi online, pada April 2019 GO-JEK kemudian menghadirkan layanan Go-Food di aplikasi GO-VIET. Namun bukan tanpa tantangan, di tahun yang sama pula, Christy Trang Le memutuskan untuk hengkang dari perusahaan setelah lima bulan menduduki jabatan sebagai pimpinan GO-VIET. Akibatnya, kursi Kepala Eksekutif perusahaan afiliasi GO-JEK di Vietnam itu kembali kosong. Hal ini terjadi untuk kedua kalinya, setelah dua direktur utama sebelum Christy juga mengundurkan diri dari posisinya, dan bahkan menuntut uang kompensasi kepada GOJEK. Meski mengklaim sudah mencatatkan lebih dari 100 juta perjalanan selama satu tahun, GOVIET sepertinya masih harus berjuang dengan masalah kepemimpinan internal, sekaligus menghadapi persaingan ketat dengan Grab dan kompetitor lokal yang lain (termasuk juga jasa transportasi seperti taxi dan xe-om atau ojek) tentunya dalam hal ini GO-JEK harus mampu untuk menjaga GO-VIET agar dapat etap bermain sesuai dengan pasar lokal.

Pada bulan Agustus 2020, GO-JEK akhirnya resmi mengganti nama GO-VIET menjadi GO-JEK Vietnam yang merupakan bagian dari upaya penggabungan layanan GO-VIET dengan GO-JEK selaku induk usahanya. GO-VIET telah bersatu dengan payung GO-JEK yang lebih besar sehingga dapat berinovasi secara lebih efektif dalam skala besar dan menciptakan solusi yang lebih terintegrasi untuk masalah kehidupan sehari-hari, terutama untuk masyarakat Asia Tenggara. Mengutip dari Techinasia, GO-JEK mengklaim telah terintegrasi dan menghubungkan pelanggan ke lebih dari 150.000 pengemudi serta 80.000 pedagang makanan di Kota Hanoi dan Ho Chi Minh. Pada waktu yang bersamaan dengan penggantian nama ini, GO-JEK di Vietnam juga menambah dan mengembangkan beberapa fiturnya, seperti mengubah tampilan home screen menjadi lebih sederhana, menambah fitur pilihan bagi pengguna untuk menandai menu makanan favorit dalam GoFood, fitur berbagi foto antara pengguna dan pengemudi, serta fitur untuk mengoperasikan banyak pesanan di lintas layanan. Pengguna di Vietnam kini dapat menikmati layanan Go-Bike, GoSend untuk logistik pengiriman barang, dan GoFood untuk pesan antar makanan melalui aplikasi GO-JEK. Sejak saat itu pengguna GO-JEK dari Indonesia, Singapura, dan Thailand dapat menggunakan aplikasi yang sama ketika berkunjung ke Vietnam dan tidak perlu melakukan instalasi aplikasi terpisah.

Perusahaan GO-JEK Indonesia sendiri semakin mengukuhkan kolaborasi yang lebih erat dengan tim GO-JEK di Thailand dan di Vietnam. Dengan menyatukan teknologi di bawah naungan induk perusahaan, GO-JEK akan dapat menghadirkan fitur dan produk baru ke pasar lebih cepat, mempercepat skala pelayanan di banyak negara (terutama negara-negara dengan tingkat kemiripan yang cukup tinggi dengan Indonesia dari berbagai aspek seperti kebutuhan masyarakat, karakteristik perilaku dan kebiasaan masyarakat, kondisi lalu lintas dan infrastruktur, serta budaya) dan meningkatkan peluang penghasilan bagi mitra. Untuk saat ini, GO-JEK telah menarik perhatian banyak investor besar baik di skala nasional maupun global, beberapa diantaranya untuk mempercayakan kerjasama dengan GO-JEK karena peluang cukup besar yang diprediksinya. Beberapa diantaranya adalah Google, Tencent, dan disusul oleh Facebook dan Paypal pada Juni 2020. Dilansir dari gojek.com, sumber daya perusahaanperusahaan teknologi terbesar di dunia ini akan disinergikan dengan teknologi, pendekatan, dan fokus lokal yang dimiliki Gojek guna mendorong adopsi sistem pembayaran digital secara cepat sehingga mendatangkan manfaat bagi jutaan usaha dan orang di Indonesia dan Asia Tenggara.

Di tahun 2020, suntikan pendanaan untuk GOJEK mendekati angka 3 miliar dollar AS (Rp 50,6 triliun). Farhad Maleki, Head of Corporate Development and Ventures for APAC, PayPal, mengatakan, "Asia Tenggara sedang berada di titik yang sangat krusial dalam proses adopsi digital yang dapat menciptakan kesempatan baru untuk memberikan layanan finansial kepada konsumen maupun penyedia layanan atau merchant yang selama ini belum terhubung ke layanan perbankan. Kami sangat bersemangat dalam memasuki sebuah hubungan strategis dengan Gojek untuk memperluas akses dan memberikan pengalaman baru bagi para pengguna kami di pasar yang sangat dinamis ini dan di seluruh dunia." 
Tabel 1. Perbandingan Prosentase Performa GO-VIET dan Grab (2018) dari 100\% Responden

\begin{tabular}{clcc}
\hline No. & \multicolumn{1}{c}{ Indikator } & Grab & $\begin{array}{c}\text { GO- } \\
\text { VIET }\end{array}$ \\
\hline 1 & Popularitas Merk & $99 \%$ & $67 \%$ \\
\hline 2 & $\begin{array}{l}\text { Popularitas } \\
\text { Layanan }\end{array}$ & $92 \%$ & $8 \%$ \\
\hline 3 & $\begin{array}{l}\text { Promosi Iklan } \\
\text { Internet }\end{array}$ & $63 \%$ & $41 \%$ \\
\hline 4 & $\begin{array}{l}\text { Persentase } \\
\text { Pelanggan Rutin }\end{array}$ & $92 \%$ & $8 \%$ \\
\hline 5 & $\begin{array}{l}\text { Persentase } \\
\text { Pelanggan Non- } \\
\text { Rutin }\end{array}$ & $29 \%$ & $98 \%$ \\
\hline 6 & $\begin{array}{l}\text { Tingkat } \\
\text { Kepuasan } \\
\text { Pelanggan }\end{array}$ & $21 \%$ & $26 \%$ \\
\hline 7 & $\begin{array}{l}\text { Tarif Layanan } \\
\text { Murah }\end{array}$ & $37 \%$ & $48 \%$ \\
\hline 8 & $\begin{array}{l}\text { Kenyamanan } \\
\text { Pelanggan }\end{array}$ & $60 \%$ & $52 \%$ \\
\hline
\end{tabular}

Sumber: Q\&Me Market Research (2018) - Diolah oleh Penulis

Tabel 1 menjelaskan perbandingan performa GO-VIET dan Grab pada tahun 2018 ketika GO-VIET masih pada fase awal beroperasi di Vietnam. Adapun persentase yang tercantum pada tabel tersebut adalah jumlah responden yang mengafirmasi indikator-indikator penelitian lapangan yang dilakukan. Dimulai dari indikator pertama, popularitas dan public recognition yang dibangun oleh Grab lebih besar ketimbang GOVIET dikarenakan Grab terlebih dahulu melakukan penetrasi pasar. Kemudian dari segi seberapa populer layanan-layanan yang disediakan, Grab mengungguli jauh, yang dimana hal ini bisa dipandang sebagai suatu gambaran dimana Grab memiliki aplikasi yang dipandang warga Vietnam lebih ramah baik dari segi antarmuka (interface) maupun kemudahan aksesibilitas untuk semua kelas usia. Dalam segi indikator promosi iklan, Grab mengungguli lebih jauh dengan margin yang tidak begitu besar. Tetapi apabila dianalisis dari indikator persentase pelanggan yang rutin menggunakan GOVIET terus menerus, memang Grab tertinggal, dan begitu juga ketika membandingkan persentase pelanggan non-rutin. Serta GO-VIET kembali unggul dengan harganya yang lebih murah dan terjangkau ketimbang Grab dan memiliki tingkat kepuasan pelanggan lebih tinggi sebesar $48 \%$ dan dari segi kenyamanan hanya berbeda tipis dengan Grab.

Dari deskripsi tersebut, maka dapat disimpulkan beberapa hal yang perlu dimengerti. Pertama, dari segi pengalaman, Grab bisa jadi memiliki jam terbang yang lebih tinggi, namun dari segi kompetisi fitur dan pengembangan layanan, GO-VIET secara imbang bisa menjadi pemain kunci dalam 2-3 tahun kedepan. Adapun kesimpulan ini dapat diambil dikarenakan GOVIET yang merupakan subsidiary dari GO-JEK memiliki etos kerja dan model bisnis yang harmonis dan sejenis, serta dengan tidak adanya perbedaan yang besar antara kondisi sosial di Vietnam dan di Indonesia.

Maka dalam hal ini GO-VIET telah memberikan citra bahwa perusahaan berbendera Indonesia mampu untuk mempertahankan momentum dan memberikan kepuasan, yang dimana akan meningkatkan jumlah pelanggan kedepannya. Namun beberapa masukan yang mungkin dapat dilihat adalah bagaimana GO-VIET dengan kehadirannya yang masih lebih muda ketimbang Grab harus memperluas jangkauan layanannya ke berbagai wilayah di Vietnam untuk meningkatkan public recognition dan melakukan penetrasi terhadap pasar-pasar yang masih cenderung dikuasai oleh Grab agar menimbulkan situasi yang kompetitif dan memberikan opsi yang lebih inovatif kepada masyarakat Vietnam. Dalam jangka panjang, Indonesia akan mampu mengungguli Singapura yang memiliki beberapa unicorn tersebar di Asia Tenggara apabila GO-JEK kedepannya akan membuka kerjasama ataupun anak perusahaan dalam bidang sejenis/ berbeda.

\section{Peluang dan Tantangan GO-VIET untuk Indonesia Kedepannya}

GO-JEK merupakan salah satu karya anak bangsa penyedia jasa berbasis transportasi online yang telah berhasil melakukan ekspansi ke beberapa negara di Asia Tenggara karena pencapaiannya yang luar biasa di Indonesia. GOJEK pada awalnya didirikan pada tahun 2010 dan hanya dapat melayani pemesanan ojek melalui call center, kemudian pada tahun 2015, GO-JEK mulai berkembang pesat dengan menjadikan GO-JEK sebuah aplikasi yang dapat diunduh di berbagai Smartphone Android maupun Ios, dengan penambahan beberapa fitur baru Go-mart, Go-send, dan Go-ride. Sejak saat itu, GO-JEK mulai berkembang menjadi grup teknologi multinasional yang menjadi pilihan jutaan masyarakat di Asia Tenggara. Vietnam merupakan destinasi pertama GO-JEK untuk melakukan ekspansi kerjasama dengan menggunakan pilihan nama GO-VIET. GOVIET resmi beroperasi di dua kota Vietnam, yaitu Ho Chi Minh City dan Hanoi. Hanoi merupakan kota kedua setelah Ho Chi Minh City yang menjadi lokasi peresmian aplikasi ini. Di Ho Chi Minh City, GO-VIET diresmikan pada Agustus 2018 (Assegaf, 2018). 
Menurut Nadiem selaku CEO dan Founder dari GO-JEK, terdapat peluang yang besar di Vietnam terkait expansi kerjasama GO-JEK, Vietnam merupakan negara dengan tolak ukur paling optimal untuk pemasaran jenis teknologi berbasis transportasi online yang terdapat di platform GO-JEK. Menurut Nadiem, populasi penduduk di Vietnam yang sangat besar, dengan angka yang hampir menyentuh 107 juta orang, serta pengguna Smartphone yang juga sangat tinggi merupakan kriteria yang sangat pas untuk mengembangkan GO-JEK. Di sisi lain, juga didukung oleh rasio dari penggunaan kendaraan roda dua atau motor oleh penduduk Vietnam yang berada di posisi paling atas di antara negara-negara lain di Asia Tenggara. Terdapat beberapa faktor lain yang menjadi peluang berkembangnya GO-JEK melalui GO-VIET di Vietnam, seperti kekhawatiran beberapa negara di Asia Tenggara, yaitu Singapura dan Filipina mengenai monopoli pasar transportasi online yang saat itu hanya didominasi oleh Grab saja, yang memungkinkan Grab dapat mengendalikan pasar dan memainkan harga. Selain itu, pesaing GO-JEK sebelumnya seperti Vato dan Grab juga telah mengalami penurunan kualitas, yang membuat 3,2 juta pengguna aktif transportasi online di Vietnam teralihkan perhatian nya.

Menurut Michael Underwood (Managing Director, Matterhorn Communication), yang telah tinggal di Ho Chi Minh City sejak 14 tahun lalu itu merasa GO-JEK dapat masuk ke Vietnam dengan peluang yang besar untuk diterima oleh masyarakat lokal yang ingin mencari alternatif baru dengan kualitas yang jauh lebih baik dari kompetitor GOJEK sebelumnya (Nugroho, 2018). Selain itu, GOJEK telah menjalankan strategi lain untuk dapat menciptakan peluang dalam melakukan ekspansi kerjasama serta nation branding atas Indonesia terhadap Vietnam melalui kerjasama-kerjasama yang dijalin oleh GO-JEK dengan perusahaan lokal di Vietnam dengan cara merger horizontal. Dengan adanya ekspansi GO-JEK di Vietnam juga, akan membuka banyak lapangan pekerjaan baru, terutama untuk mitra pengemudi atau driver. Nation branding Indonesia melalui GO-JEK di Vietnam juga memiliki peluang yang sangat besar, karena gaya hidup masyarakat lokal di Vietnam yang sudah modern, serta politik yang terbilang stabil. Ekspansi kerjasama yang dilakukan oleh GO-JEK dari Indonesia menciptakan banyak peluang dalam membawa dampak positif bagi berbagai kalangan di masyarakat dengan memupuk pertumbuhan serta perkembangan mulai dari aspek bisnis skala mikro, hingga menengah yang menghasilkan peningkatan taraf hidup dan juga penghasilan masyarakat (GOJEK, 2018).

Di samping begitu banyak nya peluang yang diciptakan dari kerjasama GO-JEK dengan
Vietnam, sehingga terbentuk GO-VIET juga terdapat beberapa tantangan yang harus dihadapi untuk mengoptimalkan peluang yang ada. Karena seperti yang sebelumnya sudah dijelaskan oleh Matthew Underwood (Managing Director, Matterhorn Communication), bahwa Uber, Grab, dan Vato kehilangan banyak pelanggan karena menurunya kualitas pelayanan dari berbagai aspek, mulai dari kelangkaan pengemudi, perilaku pengemudi (melakukan cancel), harga yang tidak stabil (harga naik ketika permintaan meningkat), dan kurang nya promo yang ditawarkan (Nugroho, 2018). Hal ini tentu saja menjadi hal krusial bagi masyarakat lokal di Vietnam yang price oriented. Selain itu, GO-VIET sebagai bentuk nation branding Indonesia melalui GO-JEK, juga harus berinovasi tinggi dalam mengembangkan kualitas nya di era globalisasi ini, dimana perkembangan teknologi semakin pesat dan canggih agar tidak tertinggal dari persaingan yang semakin ketat khusus nya bidang teknologi modern (Indra, Tusholihah, Ajeng, \& Lusiana, 2020). Nadiem Makarim selaku CEO dan Founder GO-JEK menyatakan tantangan dari ekspansi kerjasama GOJEK ke Vietnam dengan GO-VIET dan beberapa negara lainnya adalah untuk menyelaraskan organisasi sebagai satu kesatuan yang memiliki nilai (value), asas serta prinsip yang sama untuk membangun serta meningkatkan taraf kualitas dari masing-masing bangsa. Sebanyak 25.000 mitra pengemudi yang tergabung kedalam GO-VIET, merupakan tantangan tersendiri bagaimana harus mengelola dengan rapi mitra pengemudi yang terbilang banyak jumlahnya dan cukup tersebar di berbagai bagian kota maupun daerah (Fachrizal, 2018; Rahman, 2018).

\section{KESIMPULAN}

Setelah meninjau dengan apa yang dialami oleh GO-VIET serta agenda GO-JEK yang disponsori oleh pemerintahan Indonesia, maka ada beberapa hal yang dapat dipertimbangkan untuk menjelaskan konseptualisasi diatas. Pertama, Indonesia sebagai salah satu negara dengan GDP terbesar di ASEAN tentu ingin memperkuat interdependensi kepada mitra strategisnya sebagai suatu bentuk kenyataan asertif soft-power Indonesia untuk jangka panjang secara politik, ekonomi, dan sosial-budaya di ASEAN. Hal ini didukung dengan visi Presiden Joko Widodo untuk mengakomodir dan menarik investor dari negara lain untuk berinvestasi di Unicorn berbendera Indonesia dan diharapkan perusahaan-perusahaan tersebut dapat memberikan 'kehadiran' (presence) Indonesia secara melalui branding. Apalagi semenjak diimplementasikannya kerjasama ekonomi dan pembangunan yang komprehensif seperti 
Comprehensive Economic Partnership Agreement (CEPA) dapat mendorong integrasi baik perdagangan barang maupun perdagangan jasa yang lebih efisien dan tidak terhalang akan birokrasi maupun tantangan teknis. Sehingga GO-JEK dalam hal ini telah menjadi ujung tombak corporate diplomacy Indonesia dalam sektor transportasi dan mampu untuk mengikat Vietnam kedalam interdependensi politik ekonomi secara kohesif dan berkelanjutan.

Kedua, GO-VIET yang telah didirikan oleh GO-JEK terbukti memiliki dampak di masyarakat Vietnam dan mampu untuk menyaingi merek lain seperti Grab yang berasal dari Singapura. Dalam hal ini GO-VIET dengan market share sebesar 10,30\% pada tahun 2019, dan ini mengindikasikan bahwa GO-VIET adalah kompetitor Grab yang memiliki market forecast yang positif kedepannya. Secara eksperimental, hal ini didukung dengan meningkatnya demand terhadap transportasi online di tengah pandemi yang lebih murah ditengah krisis ekonomi, serta kemampuan perusahaan transportasi online seperti GO-VIET yang mampu membuka lapangan pekerjaan lebih luas untuk masyarakat menengah bawah di Vietnam. Dan ketiga, GOVIET memiliki pola perkembangan yang sejenis dengan Grab sama seperti zaman ketika transportasi online belumlah lazim. Oleh karena itu, Indonesia menjadi suatu powerhouse industri inovatif yang tidak hanya memberikan insentif yang berarti dan menekan pengangguran, namun juga sebagai negara dengan jumlah unicorn yang menguasai jaringan bisnis dan suplai di Asia Pasifik. Adapun hal ini didukung oleh politik luar negeri Presiden Joko Widodo yang menjaga momentum dan mengambil kesempatan yang strategis dan sesuai dengan norma diplomasi Indonesia, baik melalui saluran tradisional antar negara maupun yang nontradisional atau melalui komponen masyarakat dan atau korporasi yang semakin maju di dekade ini.

\section{DAFTAR PUSTAKA}

Andriani, D. (2019, Agustus 29). Jumlah Pengguna Aktif Gojek di Indonesia Setara dengan Aplikasi Ride-Sharing Terbesar Dunia. Dipetik Dari Bisnis.com: https://ekonomi.bisnis.com/read/20190829/98 /1141953/jumlah-pengguna-aktif-gojek-diindonesia-setara-dengan-aplikasi-ridesharing-terbesar-

dunia\#: :text=Per\%20semester\%201\%2F201 9\%2C\%20aplikasi,penyedia\%20layanan $\% 20$ di\%20Asia\%20Tenggara.

Araya, O. Y. (2018, September 15). Cara Go-Jek "Mendidik" Go-Viet. Dipetik Dari Kompas.com: https://tekno.kompas.com/read/2018/09/15/1

2490007/cara-go-jek-mendidik-go-viet

Bolweski, W. (2018). Corporate diplomacy as global management. International Journal of Diplomacy and Economy, 4(2), 107-138. doi:10.1504/IJDIPE.2018.10015293.

Chen, O., Song, S., \& Yao, M. Z. (2020). Brands as a nation: An analysis of overseas media engagement of top Chinese brands. Sage Journals, 22-39. doi: $10.1177 / 2059436420903110$

CNN Indonesia (2018, September 14) Rencana GoJek Merambah Pasar ASEAN [Video File]. Dipetik Dari https://youtu.be/c-1OrjXg6Q8

Cull, N. J. (2008). Public Diplomacy: Taxonomies and Histories. The ANNALS of the American Academy of Political and Social Sciences, 3154. doi:10.1177/0002716207311952

Darwis, Putra, B. A., Guido, B., Baharuddin, A., \& Burhanuddin. (2020). THE ASEAN ECONOMIC COMMUNITY AND DETERMINANT FACTORS IN THE EXPANSION OF INDONESIAN BUSINESSMEN IN THE SOUTHEAST ASIAN MARKET. Academy of Entrepreneurship Journal, 26(4), 3. ISSN: 1528-2686

Deephouse, D. (2000). Media reputation as a strategic resource: an integration of mass communication and resource-based theories. Journal of Management, 26(6), 1091-1112. doi:10.1177/014920630002600602

Drezner, D. W. (2017). Drezner, D.W. (2017). The Angry Populist as Foreign Policy Leader: Real Change or Just Hot Air? The Fletcher Forum of World Affairs, 41(2), 23-43. Dipetik Dari https://heinonline.org/HOL/LandingPage?han $\mathrm{dle}=$ hein.journals $/$ forwa $41 \& \mathrm{div}=25 \& \mathrm{id}=\& \mathrm{pa}$ $\mathrm{ge}=$

DW. (2018, September 12). Jokowi Antar Go-Jek Rebut Pasar Vietnam. Dipetik Dari Deutsche Welle (DW): https://amp.dw.com/id/jokowiantar-go-jek-rebut-pasar-vietnam/a45460666?fbclid=IwAR284iy9PMnVGZp1Z 36BQ8j2mXpYQbmufj-

NmPlzG8T_cbD_86LIQ8W64b4

Facebook, PayPal, Google dan Tencent Tanamkan Investasi di Gojek Guna Akselerasi Penggunaan Pembayaran Digital Khususnya Bagi UMKM di Indonesia. (2020, 06 03) gojek.com. Dipetik $02 \quad 02,2021$. https://www.gojek.com/blog/gojek/investorgojek/

Fachrizal, R. (2018, September 13). Inilah Beberapa Fakta Mengenai Kehadiran Go-Viet di Negara Vietnam. Dipetik Dari INFOKOMPUTER:

https://infokomputer.grid.id/read/12937158/i 
nilah-beberapa-fakta-mengenai-kehadirango-viet-di-negara-vietnam

Fida Rahman, A. (2018, September 14). Nadiem Makarim Ungkap Tantangan Go-Jek Setelah Ekspansi. Dipetik Dari detik.com: https://inet.detik.com/business/d4211521/nadiem-makarim-ungkaptantangan-go-jek-setelah-ekspansi

Fombrun, C. (1996). Reputation: Realizing Value Dari the Corporate Image . Boston: Harvard Business School.

Franedya, R. (2019, December 27). Siapa Penguasa Sejati Pasar Ojol RI, Grab atau Gojek? Dipetik Dari CNBC Indonesia: https://www.cnbcindonesia.com/tech/201912 27065254-37-125903/siapa-penguasa-sejatipasar-ojol-ri-grab-atau-gojek

Gojek. (2018, Juni 25). GO-JEK Umumkan Peluncuran Perusahaan di Vietnam (GOVIET) dan Thailand (GET) Sebagai Bagian dari Ekspansi Internasional Tahap Pertama. Dipetik Dari Gojek.com: https://www.gojek.com/blog/gojek/ekspansiinternasional-go-jek-di-vietnam-dan-thailandtahap-pertama/

Gojek. (n.d.). Gojek Tentang Kami. Dipetik Dari Gojek: https://www.gojek.com/about/

GoViet Resmi Berganti Nama Jadi Gojek Vietnam. (2020, 08, 06). techinasia.com. Dipetik 02 02, 2021, Dari https://id.techinasia.com/govietberganti-nama-jadi-gojek-vietnam

Henisz, W. (2014). ) Corporate Diplomacy: Building Reputations and Relationships with External Stakeholder. Sheffield: Greenleaf Publishing. doi:10.4324/9781351287883.

Henisz, W. J. (2016). The dynamic capability of corporate diplomacy. Global Strategy Journal, 6(3), 183-196. doi:https://doi.org/10.1002/gsj.1121.

Indo Premier. (2021, Januari 16). Pemerintah Siap Hadapi Uni Eropa Dalam Sengketa DS 592 di WTO. Dipetik Februari 1, 2021 , dari IPOTNEWS:

https://www.indopremier.com/ipotnews/news Detail.php?jdl=Pemerintah_Siap_Hadapi_Un i_Eropa_Dalam_Sengketa_DS_592_di_WTO \&news_id=129024\&group_news=IPOTNEW S\&taging_subtype $=$ PG002\&name $=\&$ search $=$ y_general\&q=,\&halaman $=1$

Indra, N., Tusholihah, M., Ajeng, S., \& Lusiana, D. (2020). Peluang Dan Tantangan Perencanaan Pembentukan Koperasi Mitra. JURNAL ILMIAH AKUNTANSI DAN KEUANGAN. doi:https://doi.org/10.32670/fairvalue.v2i2.88

Ini Alasan Gojek Ingin Berekspansi ke Asia Tenggara. (2018, 05 24). republika.co.id. Dipetik $01 \quad 29, \quad 2021$, Dari https://www.republika.co.id/berita/ekonomi/k orporasi/18/05/24/p98e62377-ini-alasangojek-ingin-berekspansi-ke-asia-tenggara

Isna, T. D. (2020, July 3). Gojek Bakal 'Lenyapkan' GoViet dan Get, Ganti Nama Jadi . . . . Dipetik Dari Warta Ekonomi: https://www.wartaekonomi.co.id/read293064/ gojek-bakal-lenyapkan-goviet-dan-get-gantinama-jadi

Jose, H. S. (2021, Januari 6). BDSC Sebagai Diplomasi Publik Untuk Demokrasi Berkelanjutan. Dipetik Januari 30, 2021, dari Kontekstual: https://kontekstual.com/bdscsebagai-diplomasi-publik-untuk-demokrasiberkelanjutan/

Kumparan. (2020, Agustus 3). Gojek Sumbang Rp 104,6 Triliun untuk Ekonomi Indonesia di 2019, GoFood Juaranya. Dipetik Dari Kumparan:

https://kumparan.com/kumparantech/gojeksumbang-rp-104-6-triliun-untuk-ekonomiindonesia-di-2019-gofood-juaranya$1 \mathrm{tvjDiFsiIq/full}$

Moore, M. (2020, September 2). Number of monthly active users (MAU) of Gojek in Southeast Asia as of November 2019, by country. Dipetik Dari Statista: https://www.statista.com/statistics/1168407/s ea-number-of-gojek-monthly-active-users/

Nugroho, W. (2018, Agustus 1). Menakar Peluang Go-Jek ketika Beroperasi di Vietnam dan Thailand. Dipetik Dari infokomputer: https://infokomputer.grid.id/read/12910109/ menakar-peluang-go-jek-ketika-beroperasidi-vietnam-dan-thailand?page=all

Olins, W. (1999). Trading identities: Why countries and companies are taking on each other's roles. London: The Foreign Policy Centre.

Potter, E. (2006). Branding Canada: Projecting Canada's Soft Power through Public Diplomacy. Montreal: McGill-Queen's University Press.

Prananda, N. I., YinFah, B. C., Chen, L. L., \& Chuen, P. W. (2020). Go-Jek Company: GoJek's Rise to Dominating Indonesian's Markets and Southeast Asean. Test Engineering and Management, 82, 735-743.

Pratama, A. H. (2016, Agustus 13). Go-Jek: A unicorn's journey (Infographic). Dipetik Februari 1, 2021 , Dari Tech in Asia: https://www.techinasia.com/how-go-jekbecame-unicorn

Ramadhani, Y. (2019, February 18). 3 Unicorn Pertama Indonesia: Gojek, Tokopedia, dan Traveloka. Dipetik Dari Tirto id: https://tirto.id/3-unicorn-pertama-indonesiagojek-tokopedia-dan-traveloka-dhfB

Q\&Me. (2018, October). Ride sharing apps popularity in Vietnam. Dipetik Februari 1, 
2021 , dari Q and Me: https://qandme.net/en/report/ride-sharingapps-popularity-vietnam.html

Savithri, A. (2018, January 2018). Google Suntik Dana Segar Rpl6 Triliun untuk Gojek. Dipetik Dari CNN Indonesia: https://www.cnnindonesia.com/teknologi/201 80118145516-185-269890/google-suntikdana-segar-rp16-triliun-untuk-gojek

Scherer, A., Palazzo, G., \& Baumann, D. (2006). Global rules and private actors - towards a new role of the TNC in the global governance. Business Ethics Quarterly, 505-550. doi: $10.2307 / 3857794$

Schiller, H. (1989). Culture, incorporated: The corporate takeover of public expression. New York: Oxford University Press.

Sodiq Assegaf, J. (2018, September 13). Go-Viet, Go-Jek di Vietnam Resmi Beroperasi. Dipetik Dari solopos.com: https://www.solopos.com/go-viet-go-jek-divietnam-resmi-beroperasi-939404

Szondi, G. (2008, October). Public Diplomacy and Nation Branding: Conceptual Similiarities and Differences. Discussion Papers in Diplomacy. Dipetik

Dari https://www.kamudiplomasisi.org/pdf/nation branding.pdf

Van Ham, P. (2001). The Rise of the Brand State: The Postmodern Politics of Image and Reputation. Foreign Affairs, 80(5), 2-6. doi:https://doi.org/10.2307/20050245

Verhoeven, B., \& Johnson, L. W. (2017). Business Model Innovation Portfolio Strategy for Growth Under Product-Market Configurations. Journal of Business Models, 5(1), 35-50. doi:https://doi.org/10.5278/ojs.jbm.v5i1.1924

Wang, J. (2006). Public Diplomacy and Global Business. The Journal of Business Strategy, 27(3), 49-58.

Zaenudin, A. (2019, April 5). Go-Jek Jadi Decacorn, Unicorn adalah Masa Lalu. Dipetik Dari Tirto id: https://tirto.id/go-jekjadi-decacorn-unicorn-adalah-masa-lalu-dlfA 